\title{
SCS-CN parameter determination using rainfall-runoff data in heterogeneous watersheds - the two-CN system approach
}

\author{
K. X. Soulis and J. D. Valiantzas \\ Agricultural University of Athens, Department of Natural Resources Management and Agricultural Engineering, \\ Division of Water Resources Management, Athens, Greece
}

Correspondence to: K. X. Soulis (soco@aua.gr)

Received: 5 September 2011 - Published in Hydrol. Earth Syst. Sci. Discuss.: 5 October 2011

Revised: 1 February 2012 - Accepted: 16 March 2012 - Published: 28 March 2012

\begin{abstract}
The Soil Conservation Service Curve Number (SCS-CN) approach is widely used as a simple method for predicting direct runoff volume for a given rainfall event. The $\mathrm{CN}$ parameter values corresponding to various soil, land cover, and land management conditions can be selected from tables, but it is preferable to estimate the $\mathrm{CN}$ value from measured rainfall-runoff data if available. However, previous researchers indicated that the $\mathrm{CN}$ values calculated from measured rainfall-runoff data vary systematically with the rainfall depth. Hence, they suggested the determination of a single asymptotic $\mathrm{CN}$ value observed for very high rainfall depths to characterize the watersheds' runoff response. In this paper, the hypothesis that the observed correlation between the calculated $\mathrm{CN}$ value and the rainfall depth in a watershed reflects the effect of soils and land cover spatial variability on its hydrologic response is being tested. Based on this hypothesis, the simplified concept of a two-CN heterogeneous system is introduced to model the observed $\mathrm{CN}$ rainfall variation by reducing the $\mathrm{CN}$ spatial variability into two classes. The behaviour of the $\mathrm{CN}$-rainfall function produced by the simplified two-CN system is approached theoretically, it is analysed systematically, and it is found to be similar to the variation observed in natural watersheds. Synthetic data tests, natural watersheds examples, and detailed study of two natural experimental watersheds with known spatial heterogeneity characteristics were used to evaluate the method. The results indicate that the determination of $\mathrm{CN}$ values from rainfall runoff data using the proposed two$\mathrm{CN}$ system approach provides reasonable accuracy and it over performs the previous methods based on the determination of a single asymptotic $\mathrm{CN}$ value. Although the suggested method increases the number of unknown parameters to three (instead of one), a clear physical reasoning for them is presented.
\end{abstract}

\section{Introduction}

Simple methods for predicting runoff from watersheds are particularly important in hydrologic engineering and hydrological modelling and they are used in many hydrologic applications, such as flood design and water balance calculation models (Abon et al., 2011; Steenhuis et al., 1995; van Dijk, 2010). The Soil Conservation Service Curve Number (SCS-CN) method was originally developed by the SCS (US Department of Agriculture), to predict direct runoff volumes for given rainfall events and it is documented in the National Engineering Handbook, Sect. 4: Hydrology (NEH-4) (SCS, 1956, 1964, 1971, 1985, 1993, 2004). It soon became one of the most popular techniques among the engineers and the practitioners, because it is a simple but well-established method, it features easy to obtain and well-documented environmental inputs, and it accounts for many of the factors affecting runoff generation, incorporating them in a single $\mathrm{CN}$ parameter. In contrast, the main weaknesses reported in the literature are that the SCS-CN method does not consider the impact of rainfall intensity, it does not address the effects of spatial scale, it is highly sensitive to changes in values of its single parameter, $\mathrm{CN}$, and it is ambiguous considering the effect of antecedent moisture conditions (Hawkins, 1993; McCuen, 2002; Michel et al., 2005; Ponce and Hawkins, 1996).

The SCS-CN method was soon adopted for various regions, land uses and climate conditions (Elhakeem and $\mathrm{Pa}$ panicolaou, 2009; King and Balogh, 2008; Mishra and Singh, 1999; Romero et al., 2007). It was also evolved well beyond its original scope and it became an integral part of continuous simulation models (e.g. Adornado and Yoshida, 2010; Holman et al., 2003; Mishra and Singh, 2004; Moretti and Montanari, 2008; Soulis and Dercas, 2007). Many 
studies aiming at finding a theoretical basis for the method, facilitating its use in regions and for climate conditions not previously evaluated, and supporting its further improvement, were carried out as well (Hjelmfelt, 1991; Tramblay et al., 2010; Yu, 1998).

However, in spite of its widespread use, there is not an agreed methodology to estimate the $\mathrm{CN}$ parameter values from measured rainfall runoff data. Such a method would be important for two main purposes: (a) it would allow the determination of the $\mathrm{CN}$ parameter values from measured rainfall runoff data of local or nearby similar watersheds when suitable data were available and (b) it would facilitate studies aiming at the extension of the SCS-CN method documentation for different, soil, land use, and climate conditions. Though, the main difficulty is that the $\mathrm{CN}$ values calculated from measured rainfall runoff data actually vary significantly from storm to storm on any watershed. This effect posed in doubt the adequacy of curve number model itself to predict runoff. Antecedent Moisture Condition (AMC) was initially assumed to be the primary cause of storm to storm variation. However, this effect is of questionable origin and it is not recommended for use anymore (Hjelmfelt et al., 2001; McCuen, 2002; Ponce and Hawkins, 1996). In the latest version of the NEH-4 the reference to AMC was revised as follows. Variability is incorporated by considering the $\mathrm{CN}$ as a random variable and the AMC-I and AMC-III categories as bounds of the distribution. The expressions of AMC-I and AMC-III were considered as measures of dispersion around the constant tendency (AMC-II) (Hjelmfelt et al., 2001).

Ponce and Hawkins (1996) reported as possible sources of this variability the effect of the temporal and spatial variability of storm and watershed properties, the quality of the measured data, and the effect of antecedent rainfall and associated soil moisture. Soulis et al. (2009) and Steenhuis et al. (1995) also noted that the variation of $\mathrm{CN}$ value, according to AMC category alone, cannot justify the observed $\mathrm{CN}$ values variability in every case.

Hawkins (1993) in his study on the asymptotic determination of runoff curve numbers from measured runoff analysing a significantly large number of watersheds, where CNs are calculated from real rainfall-runoff data, concluded that a secondary systematic correlation almost always emerges in watersheds between the calculated $\mathrm{CN}$ value and the rainfall depth. In most of the watersheds, these calculated CNs approach a constant value with increasing rainfall depth that is assumed to characterize the watershed. The three different behaviours that have been observed are described as follows: the most common scenario is that at small rainfall depths correspond larger values of calculated CNs, which decline progressively with increasing storm size, approaching a stable near constant asymptotic $\mathrm{CN}$ value with increasingly larger storms. This behaviour appears most frequently and it is characterized as "standard". An example of this pattern is given in Fig. 1. Hawkins (1993) suggests the identification of a single asymptotic $\mathrm{CN}$ value observed for very large

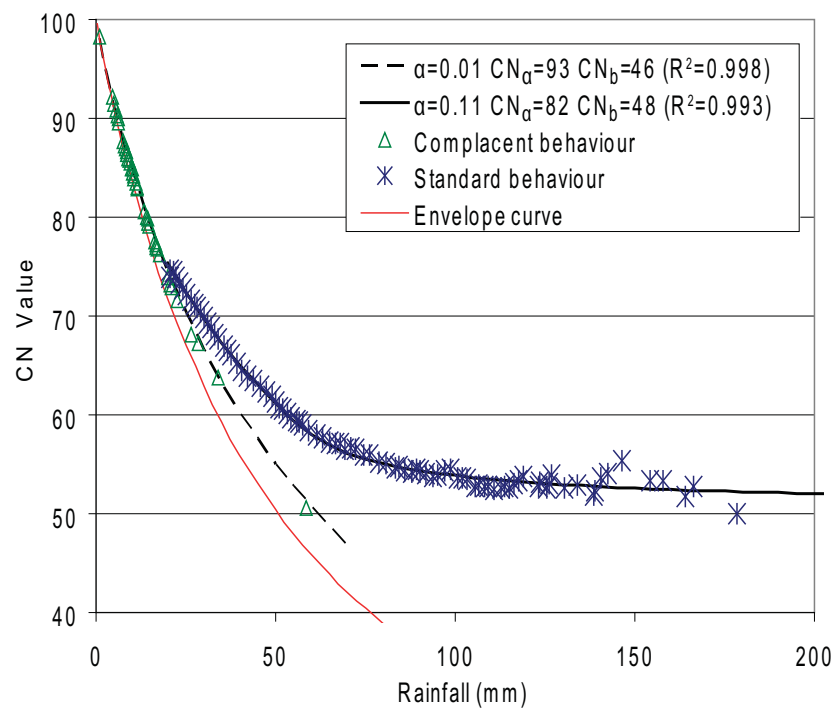

Fig. 1. Two-CN system model curves fitted to the data presented by Hawkins (1993) for the "standard" (Coweeta watershed \#2, North Carolina) and the "complacent" (West Donaldson Creek, Oregon) behaviour watersheds.

storm sizes to characterize such watersheds. In less common cases of watersheds the observed $\mathrm{CN}$ declines steadily with increasing rainfall with no appreciable tendency to approach a constant value ("complacent" behaviour, Fig. 1). According to Hawkins (1993), an asymptotic CN cannot be safely determined from data for this behaviour. In the last case, concerning also a small number of watersheds, the calculated CNs have an apparently constant value for all rainfall depths except very low rainfall depths where $\mathrm{CN}$ increases suddenly ("violent" behaviour).

Additional examples of watersheds featuring similar behaviours are presented by Hjelmfeld et al. (2001). Bonta (1997) proposed an improvement to the Hawkins (1993) method for the asymptotic determination of CNs from measured data in "violent" and "standard" watersheds using derived distributions.

All previously developed methodologies for estimating CNs from measured data focus mainly on the determination of a single asymptotic $\mathrm{CN}$ value characterizing the watershed hydrologic response for high rainfall depths. The observed deviations from the asymptotic behaviour for lower rainfall depths are not essentially taken into consideration and are rather attributed to various sources of temporal variability. For this reason, the resulting $\mathrm{CN}$ values fail to describe the watershed response in small and medium rainfall events, limiting the applicability of the method to its original scope, namely the estimation of peak runoff values. Furthermore, the above methods fail to determine a final $\mathrm{CN}$ value in "complacent" watersheds. The $\mathrm{CN}$ varies as a function of the soil infiltration capacity and the land cover of the watershed, which are two essentially time invariant factors. 
Various sources of temporal variability, such as the effect of spatio-temporal rainfall intensity variability, the effect of antecedent rainfall, etc., make $\mathrm{CN}$ to be considered as a random variable with bounds of distribution AMC-I and AMC-III. The SCS-CN method was originally developed as a lumped model and up to this date it is still primarily used as a lumped model. In natural watersheds, however, spatial variability (at lower or higher level) with regard to the soil-cover complex is inevitable (such spatial heterogeneity in the watershed could be considered temporally invariant).

In this paper, a novel hypothesis is proposed suggesting that the intrinsic correlation between calculated $\mathrm{CN}$ value and rainfall depth observed in watersheds corresponding to the "standard" and "complacent" cases is essentially the natural consequence of the presence of soils and land cover spatial variability along the watersheds. It is shown that the presence of spatial variability (at low or high level) in the watersheds produces a progressive decrease in the calculated $\mathrm{CNs}$ as the storm size decreases and for excessively large storm sizes the $\mathrm{CN}$ tends to stabilize in an asymptotic $\mathrm{CN}$ value. The proposed hypothesis is approached theoretically, it is analysed systematically using synthetic data, it is studied in two natural experimental watersheds with known spatial heterogeneity characteristics and it is evaluated using natural watersheds examples. The results of the analysis provide evidence that the spatial variability of the watershed can influence the $\mathrm{CN}$ determination procedure from measured rainfall-runoff data and that the estimation of more than one $\mathrm{CN}$ values is needed in order to describe the spatial variability of the watershed and to facilitate the determination procedure. Based on the above hypothesis, the simplified concept of an equivalent two- $\mathrm{CN}$ heterogeneous system is introduced to model the $\mathrm{CN}$ vs. rainfall depth variation. This new evolution takes into consideration the soil-cover complex spatial variation in the estimation of $\mathrm{CN}$ values from measured rainfall-runoff data, in order to extend the applicability of the SCS-CN method for a wider range of rainfall depths and to provide improved simulations in heterogeneous watersheds.

\section{Theoretical development}

\subsection{SCS-CN method}

The SCS-CN method is based on the following basic form calculating runoff from rainfall depth,

$Q=\frac{\left(P-I_{\mathrm{a}}\right)^{2}}{P-I_{\mathrm{a}}+S}$ for $P>I_{\mathrm{a}}$
$Q=0 \quad$ for $P \leq I_{\mathrm{a}}$

where $P$ is the total rainfall, $I_{\mathrm{a}}$ is the initial abstraction, $Q$ is the direct runoff and $S$ is the potential maximum retention. Based on a second assumption, that the amount of initial abstraction is a fraction of the potential maximum retention

$I_{\mathrm{a}}=\lambda S$
Eq. (1) becomes

$Q=\frac{(P-\lambda S)^{2}}{P+(1-\lambda) S}$

The potential retention $S$ is expressed in terms of the dimensionless curve number $(\mathrm{CN})$ through the relationship

$S=\frac{1000}{\mathrm{CN}}-10$

taking values from 0 , when $S \rightarrow \infty$, to 100 , when $S=0$. This definition was originally applied to the English metric system (with $S$ in inches). In the SI units (with $S$ in $\mathrm{mm}$ ) the following definition should be used:

$S=\frac{25400}{\mathrm{CN}}-254$

The determination of all the NEH-4 SCS-CN values commonly used in hydrologic practice, assume the initial abstraction rate to be set to the constant value, $\lambda=0.2$, in order that $S$ (or its transformation $\mathrm{CN}$ ) remains the only free unknown parameter of the method. Recently, Woodward et al. (2003) analysing event rainfall-runoff data from several hundred plots recommended using $\lambda=0.05$.

The $\mathrm{CN}$ values corresponding to the various soil types, land cover and land management conditions can be selected from the NEH-4 tables. However, it is preferable to estimate the $\mathrm{CN}$ value from recorded rainfall-runoff data from local or nearby similar watersheds. When rainfall-runoff data are available for a watershed, $P$ and $Q$ pairs are used directly to determine the potential retention $S$ characterizing the watershed (Chen, 1982)

$S=\frac{P}{\lambda}+\frac{(1-\lambda) Q-\sqrt{(1-\lambda)^{2} Q^{2}+4 \lambda P Q}}{2 \lambda^{2}}$

Combining Eq. (4b) with Eq. (5), CN value can be directly calculated from rainfall-runoff data

$\mathrm{CN}=\frac{25400}{\frac{P}{\lambda}+\frac{(1-\lambda) Q-\sqrt{(1-\lambda)^{2} Q^{2}+4 \lambda P Q}}{2 \lambda^{2}}+254}$

\subsection{Runoff prediction errors related to the use of single composite $\mathrm{CN}$ values}

Grove et al. (1998) in their study investigated the effect of using single composite $\mathrm{CN}$ values (i.e. the area-weighted average of the $\mathrm{CN}$ values in the watershed) instead of weighted runoff estimates, indicating that significant errors in runoff estimates can occur when composited rather than distributed CNs are used. Lantz and Hawkins (2001) also discussed the possible errors caused by the use of a single composite $\mathrm{CN}$ value.

The main reason for the errors produced using the composite $\mathrm{CN}$ value instead of weighted- $Q$ is the non-linear form of the SCS-CN formula. As an example, the case of a virtual watershed divided into two equal sub-areas characterized 

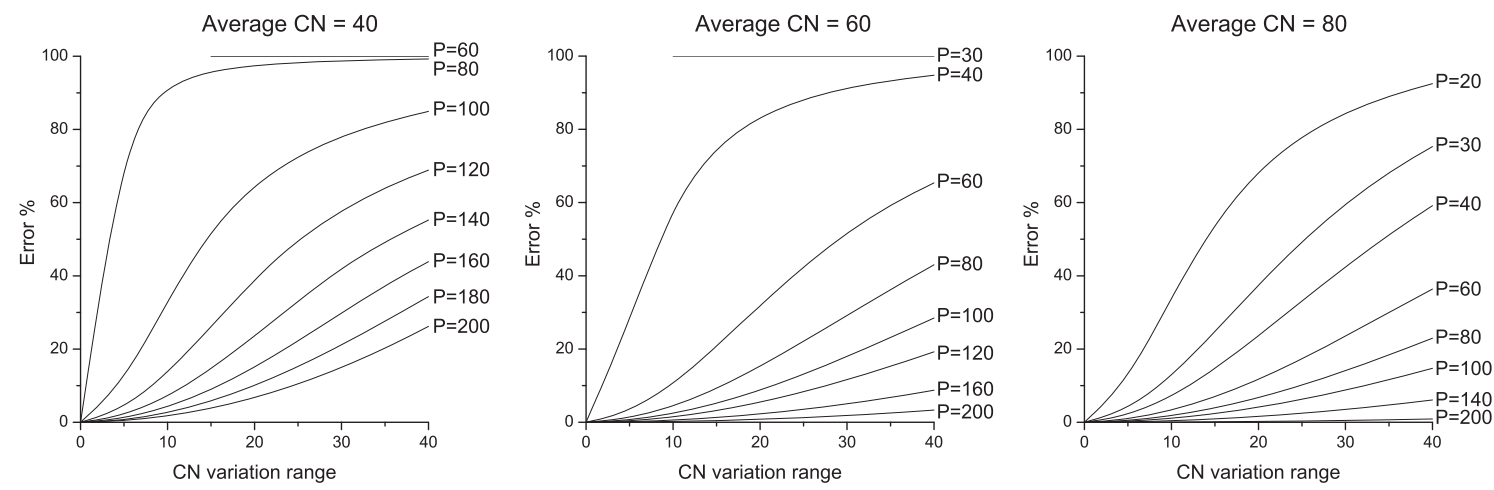

Fig. 2. Relative percentage error against the range of $\mathrm{CN}$ variation, for various total rainfall depths and for various average $\mathrm{CN}$ values.

by different $\mathrm{CN}$ values is illustrated in Fig. 2. In this figure the relative percentage error of the runoff predictions using a single composite $\mathrm{CN}$ value is plotted against the range of $\mathrm{CN}$ variation, for various total rainfall depths and for various average $\mathrm{CN}$ values. The above figure clearly illustrates that the percentage error increases as the range of $\mathrm{CN}$ variation increases and decreases as the average $\mathrm{CN}$ value and the rainfall depth increase. It is also clearly shown that for low rainfall depths significant errors are observed, even for small $\mathrm{CN}$ variation ranges. These results are in agreement with the results of Grove et al. (1998).

\subsection{The two-CN heterogeneous system}

In order to investigate the consequence of spatial variability on the $\mathrm{CN}$ vs. $P$ relationship in a watershed, in a first stage of the analysis it is assumed the simplified scheme, according to which the entire area of the watershed under consideration is composed from relatively homogeneous sub-areas. Each sub-area is assigned a $\mathrm{CN}$ value obtained from a specific set of two $\mathrm{CN}$ values $\mathrm{CN}_{\mathrm{a}}$ and $\mathrm{CN}_{\mathrm{b}}$ with $\mathrm{CN}_{\mathrm{a}}>\mathrm{CN}_{\mathrm{b}}$. If $a$ denotes the area fraction of the watershed with $\mathrm{CN}=\mathrm{CN}_{\mathrm{a}}$, then $(1-a)$ is the area fraction of the watershed with $\mathrm{CN}=\mathrm{CN}_{\mathrm{b}}$. It seems obvious that $\mathrm{CN}$ must be taken constant for a relatively homogeneous soil-cover complex. Various temporal effects such as the effect of the spatiotemporal variability of given storm, the effect of storm intensity, the effect of antecedent rainfall and others are considered as random effects on the $\mathrm{CN}$ calculation.

Traditionally the runoff equation for a heterogeneous watershed is described by using a single composite value of the different $\mathrm{CN}$-areas, this being an area- weighted $\mathrm{CN}$ value. However, runoff is more accurately estimated using individually calculated weighted runoff for the array of different subareas as it was shown in the previous section. Therefore, the runoff, $Q$ responded to the causative rainfall event, $P$ generated by the two-CN system is described by the following equation,

$Q=0$ for $P<\lambda S_{\mathrm{a}}$

$$
\begin{aligned}
& Q=a \frac{\left(P-\lambda S_{\mathrm{a}}\right)^{2}}{\left[P+(1-\lambda) S_{\mathrm{a}}\right]} \text { for } \lambda S_{\mathrm{a}} \leq P<\lambda S_{\mathrm{b}} \\
& Q=a \frac{\left(P-\lambda S_{\mathrm{a}}\right)^{2}}{\left[P+(1-\lambda) S_{\mathrm{a}}\right]}+(1-a) \frac{\left(P-\lambda S_{\mathrm{b}}\right)^{2}}{\left[P+(1-\lambda) S_{\mathrm{b}}\right]}
\end{aligned}
$$$$
\text { for } P \geq \lambda S_{\mathrm{b}}
$$

where $S_{\mathrm{a}}$ and $S_{\mathrm{b}}$ are the potential maximum retention values corresponding to the two homogeneous sub-areas characterized by the $\mathrm{CN}_{\alpha}$ and $\mathrm{CN}_{\mathrm{b}}$ values respectively, and $\lambda$ is a constant value (usually $\lambda=0.2$ or $\lambda=0.05$ ). $S_{\mathrm{a}}$ and $S_{\mathrm{b}}$ are calculated from the corresponding $\mathrm{CN}$ values using Eq. (4b).

Following, it will be pointed out that such a two-CN heterogeneous system is characterized by a secondary relationship that always emerges between calculated $\mathrm{CN}$ and rainfall depth, $P$. The particular behaviour of this relationship will be analysed in detail as well.

It is considered that for various rainfall events of depth $P$, realized on the two-CN heterogeneous system, the corresponding "actual" observed runoff, $Q$, is obtained by Eq. (7a, $\mathrm{b}, \mathrm{c})$. Then the $\mathrm{CN}$ for this system can be calculated by Eq. (6) containing only $P$ and $Q$; thus any "realized" $P-Q$ data pair can be used to calculate what should be the $\mathrm{CN}$ for that particular rainfall-runoff event in the heterogeneous system.

\subsubsection{Large- $P$ behaviour - Asymptotic $\mathrm{CN}$}

Equation $(7 \mathrm{c})$ can be standardized by using the reduced variables $\left(P / S_{\mathrm{a}}\right)$, and $\left(P / S_{\mathrm{b}}\right),\left(S_{\mathrm{a}}<S_{\mathrm{b}}\right)$. The resulting relationship becomes:

$$
Q=a S_{\mathrm{a}} \frac{\left(P / S_{\mathrm{a}}-\lambda\right)^{2}}{\left[P / S_{\mathrm{a}}+(1-\lambda)\right]}+(1-a) S_{\mathrm{b}} \frac{\left(P / S_{\mathrm{b}}-\lambda\right)^{2}}{\left[P / S_{\mathrm{b}}+(1-\lambda)\right]}
$$

for $P \geq \lambda S_{\mathrm{b}}$

while using the auxiliary variables $X_{1}=P / S_{\mathrm{a}}+(1-\lambda)$ and $X_{2}=P / S_{\mathrm{b}}+(1-\lambda)$ Eq. (8) becomes

$Q=a S_{\mathrm{a}}\left[X_{1}+1 / X_{1}-2\right]+(1-a) S_{\mathrm{b}}\left[X_{2}+1 / X_{2}-2\right]$ 
For asymptotic large values of $P$ and consequently asymptotic large values of $X_{1}$ and $X_{2}$, the corresponding value of $Q_{\infty}$ approaches asymptotically the value

$Q_{\infty}=a S_{\mathrm{a}}\left[P / S_{\mathrm{a}}+(1-\lambda)\right]+(1-a) S_{\mathrm{b}}\left[P / S_{\mathrm{b}}+(1-\lambda)\right]$

or equivalently

$Q_{\infty}=P-(1-\lambda)\left[a S_{\mathrm{a}}+(1-a) S_{\mathrm{b}}\right]$

By following a similar procedure assuming a perfectly uniform watershed characterized by a single $\mathrm{CN}$-value (or its simple transformed $S$ ), the value of $Q_{\infty}$ for large values of $P$ approaches asymptotically

$Q_{\infty}=P-(1-\lambda) S$

By putting $S_{\infty}=a S_{\mathrm{a}}+(1-a) S_{\mathrm{b}}$ in Eq. (11) the two-CN heterogeneous system behave asymptotically for large $P$ values as a single $\mathrm{CN}$ value system with equivalent potential retention $S_{\infty}$ and equivalent $\mathrm{CN}$ value

$\mathrm{CN}_{\infty}=\frac{25400}{a S_{\mathrm{a}}+(1-a) S_{\mathrm{b}}+254}$

Only for large values of $P$ the heterogeneous system can be characterized by a single asymptotic $\mathrm{CN}$ value that could be obtained using the specific "composite" CN value (Eq. 13). However, even in this case this asymptotic value does not characterize a single specific soil but it is the superposition of different complexes.

Systematic analysis indicates that the value of $\mathrm{CN}_{\infty}$ given by Eq. (13) is sufficiently close to the usual composite $\mathrm{CN}$ value

$\mathrm{CN}_{\infty}=a \mathrm{CN}_{\mathrm{a}}+(1-a) \mathrm{CN}_{\mathrm{b}}$

Further analysis based on systematic generation of $Q-P$ synthetic data for various combinations of $a, \mathrm{CN}_{\mathrm{a}}$ and $\mathrm{CN}_{\mathrm{b}}$ input parameters characterizing the two-CN system indicates that $\mathrm{CN}$ approaches the asymptotic value given by Eq. (13) for unrealistic, extremely large values of $P, P>3000 \mathrm{~mm}$. Alternatively the $\mathrm{CN}$ approaches the composite asymptotic value given by Eq. (14) for more realistic large values of $P$. Note that the composite value given by Eq. (14) is traditionally used to characterize an heterogeneous system by a single- $\mathrm{CN}$ value.

\subsubsection{Low- $P$ behaviour - Envelope curve}

For a two-CN system, as $P$ decreases the calculated values of $\mathrm{CN}$ increase, as illustrated in Fig. 3. For some threshold value of $P$,

$P_{\mathrm{o}}=\lambda S_{\mathrm{a}}$

the $\mathrm{CN}$ value becomes maximum equal to the larger $\mathrm{CN}$ category, $\mathrm{CN}_{\mathrm{a}}$, whereas for any smaller $P<P_{\mathrm{o}}$ value the $\mathrm{CN}$ is not defined since it will give no runoff $Q=0$. Indeed for

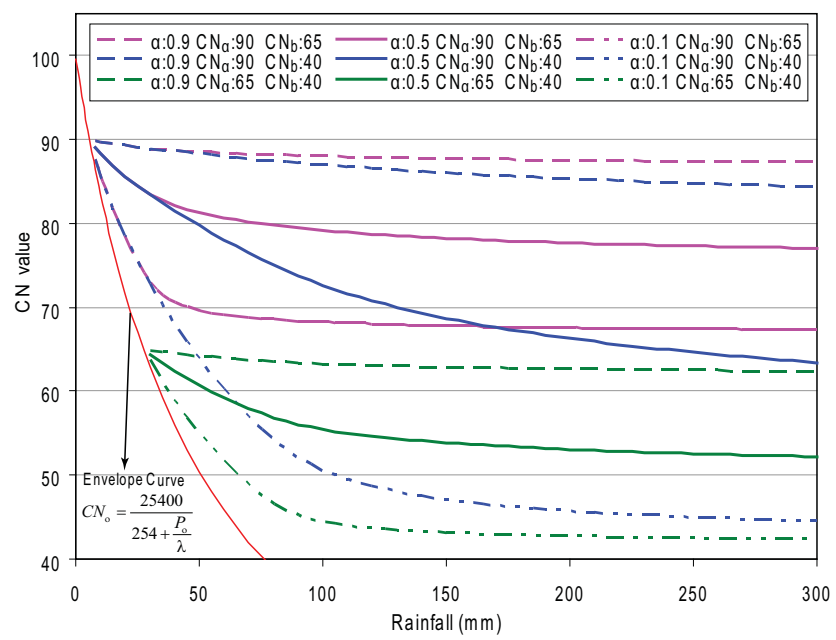

Fig. 3. Calculated $\mathrm{CN}$ values against rainfall depth for various values of the $a, \mathrm{CN}_{\mathrm{a}}$, and $\mathrm{CN}_{\mathrm{b}}$ parameters.

$P-Q$ pairs generated by Eq. (7a, b, c), when $P$ decreases approaching asymptotically the value of $P_{\mathrm{o}}$, then $Q \rightarrow 0$ therefore the asymptotic threshold value of $S, S_{0}$, calculated by Eq. (5) is $S_{\mathrm{o}}=P_{\mathrm{o}} / \lambda$. Since $S_{\mathrm{a}}$ is also given by $S_{\mathrm{a}}=P_{\mathrm{o}} / \lambda$, therefore the threshold value of $\mathrm{CN}, \mathrm{CN}_{\mathrm{o}}=\mathrm{CN}_{\mathrm{a}}$. The values of threshold maximum curve number, $\mathrm{CN}_{\mathrm{o}}$ as function of $P_{\mathrm{o}}$ is given as

$\mathrm{CN}_{\mathrm{o}}=\frac{25400}{254+\frac{P_{\mathrm{o}}}{\lambda}}$

The threshold $\mathrm{CN}_{\mathrm{o}}\left(P_{\mathrm{o}}\right)$ curve is an envelope curve that could be interpreted as the intrinsic $\mathrm{CN}(P)$ variation for a two- $\mathrm{CN}$ system with asymptotic characteristics $\mathrm{CN}_{\mathrm{a}} \rightarrow 100, \mathrm{CN}_{\mathrm{b}} \rightarrow$ 0 , and $a \rightarrow 0$. It is the curve defining the position of max $\mathrm{CN}_{\mathrm{o}}=\mathrm{CN}_{a}$ value at the threshold $P=P_{\mathrm{o}}=\lambda S_{\mathrm{a}}$ (see Figs. 1 and 3)

\subsubsection{Illustration of the two-CN heterogeneous system behaviour}

In order to illustrate the behaviour of the secondary relationship between the calculated $\mathrm{CN}$ and the rainfall depth, $P$ in the above described two-CN heterogeneous system, "actual" observed runoff values, $Q$, were obtained by Eq. (7a, b, c) for various rainfall depths $P$, by varying systematically the $a, \mathrm{CN}_{\mathrm{a}}$, and $\mathrm{CN}_{\mathrm{b}}$ parameters. Then the corresponding $\mathrm{CN}$ values for this system were calculated by Eq. (6) and a series of $\mathrm{CN}-P$ curves were produced. It must be noticed that hereafter, the standard case of $\lambda=0.2$ is examined. However, the following analysis is also valid for other $\lambda$ values, as well.

In Fig. 3 the calculated $\mathrm{CN}$ values for the various values of $a, \mathrm{CN}_{\mathrm{a}}$, and $\mathrm{CN}_{\mathrm{b}}$ parameters are plotted against the rainfall depth $P$. In this figure, a significant variation of the estimated $\mathrm{CN}$ values for various rainfall depths can be observed. The variation increases as the difference between $\mathrm{CN}_{\mathrm{a}}$ and 
Table 1. Characteristics of 21 examples of hypothetical watersheds that are characterized by three $\mathrm{CN}$ value categories and best fitted values of the $a, \mathrm{CN}_{\mathrm{a}}$, and $\mathrm{CN}_{\mathrm{b}}$ parameters.

\begin{tabular}{|c|c|c|c|c|c|c|c|c|c|c|}
\hline \multirow{3}{*}{$\begin{array}{l}\text { no. } \\
1\end{array}$} & \multicolumn{6}{|c|}{$\begin{array}{c}\text { Actual values } \\
\text { (3 CN value categories) }\end{array}$} & \multicolumn{4}{|c|}{$\begin{array}{c}\text { Fitted values } \\
\text { (Two-CN model) }\end{array}$} \\
\hline & \multicolumn{3}{|c|}{ Area $(\%)$} & \multicolumn{3}{|c|}{ Cor. CN Values } & \multirow{2}{*}{$\begin{array}{r}a \\
0.15\end{array}$} & \multirow{2}{*}{$\begin{array}{r}\mathrm{CN}_{\alpha} \\
88\end{array}$} & \multirow{2}{*}{$\frac{\mathrm{CN}_{\mathrm{b}}}{56}$} & \multirow{2}{*}{$\frac{R^{2}}{0.99}$} \\
\hline & 10 & 80 & 10 & 30 & 60 & 90 & & & & \\
\hline 2 & 33 & 33 & 33 & 30 & 60 & 90 & 0.43 & 88 & 40 & 0.99 \\
\hline 3 & 10 & 10 & 80 & 30 & 60 & 90 & 0.83 & 90 & 39 & 0.99 \\
\hline 4 & 80 & 10 & 10 & 30 & 60 & 90 & 0.14 & 87 & 32 & 0.99 \\
\hline 5 & 40 & 40 & 20 & 30 & 60 & 90 & 0.32 & 86 & 40 & 0.99 \\
\hline 6 & 20 & 40 & 40 & 30 & 60 & 90 & 0.49 & 89 & 45 & 0.99 \\
\hline 7 & 40 & 20 & 40 & 30 & 60 & 90 & 0.47 & 89 & 36 & 0.99 \\
\hline 8 & 10 & 80 & 10 & 60 & 75 & 90 & 0.16 & 89 & 73 & 0.99 \\
\hline 9 & 33 & 33 & 33 & 60 & 75 & 90 & 0.41 & 89 & 65 & 0.99 \\
\hline 10 & 10 & 10 & 80 & 60 & 75 & 90 & 0.82 & 90 & 65 & 0.99 \\
\hline 11 & 80 & 10 & 10 & 60 & 75 & 90 & 0.13 & 89 & 61 & 0.99 \\
\hline 12 & 40 & 40 & 20 & 60 & 75 & 90 & 0.29 & 89 & 65 & 0.99 \\
\hline 13 & 20 & 40 & 40 & 60 & 75 & 90 & 0.48 & 89 & 68 & 0.99 \\
\hline 14 & 40 & 20 & 40 & 60 & 75 & 90 & 0.45 & 90 & 63 & 0.99 \\
\hline 15 & 10 & 80 & 10 & 30 & 45 & 60 & 0.15 & 58 & 43 & 0.99 \\
\hline 16 & 33 & 33 & 33 & 30 & 45 & 60 & 0.44 & 59 & 35 & 0.99 \\
\hline 17 & 10 & 10 & 80 & 30 & 45 & 60 & 0.83 & 60 & 34 & 0.99 \\
\hline 18 & 80 & 10 & 10 & 30 & 45 & 60 & 0.14 & 58 & 31 & 0.99 \\
\hline 19 & 40 & 40 & 20 & 30 & 45 & 60 & 0.32 & 58 & 35 & 0.99 \\
\hline 20 & 20 & 40 & 40 & 30 & 45 & 60 & 0.5 & 59 & 37 & 0.99 \\
\hline 21 & 40 & 20 & 40 & 30 & 45 & 60 & 0.47 & 59 & 33 & 0.99 \\
\hline
\end{tabular}

$\mathrm{CN}_{\mathrm{b}}$ parameters value increases and decreases as the rainfall depth and the weighted $\mathrm{CN}$ value increase. It is clearly shown as well that for very high weighted $\mathrm{CN}$ values, the estimated $\mathrm{CN}$ value is almost invariable. It can be observed that the factors associated with significant variation of the estimated $\mathrm{CN}$ values for various rainfall depths, are also associated with significant errors when runoff estimations are made using composited rather than distributed CNs, as it was shown in Sect. 2.2. This observation provides a strong indication that the observed correlation between the calculated $\mathrm{CN}$ values and the rainfall depth should be associated with the presence of soil-cover complex spatial variability in the watershed.

In Fig. 3 can be also observed that the shapes of the $\mathrm{CN}-P$ curves produced by the two- $\mathrm{CN}$ heterogeneous system are quite similar with the shapes of the "standard" and "complacent" watersheds correlation curves presented by Hawkins (1993). When $Q-P$ data are available, the two$\mathrm{CN}$ system can be viewed as a fitting model to the transformed $\mathrm{CN}-P$ data with free parameters $a, \mathrm{CN}_{\mathrm{a}}$, and $\mathrm{CN}_{\mathrm{b}}$ (the equations of the two-CN system fitting model that can be used in a non-linear least squared procedure, are given in the Appendix A). Thus, in order to highlight further the similarity observed in Fig. 3, the two-CN hypothetical watershed curves were fitted to the $\mathrm{CN}-\mathrm{P}$ curves presented by
Hawkins (1993) as examples of the "standard" (Coweeta watershed \#2, North Carolina) and of the "complacent" (West Donaldson Creek, Oregon) behaviour, by adjusting the values of the $a, \mathrm{CN}_{\mathrm{a}}$, and $\mathrm{CN}_{\mathrm{b}}$ parameters. As it can be clearly seen in Fig. 1, the CN-P curves are fitted very well by the two-CN system model in both cases. These results provide further evidence that the spatial variability of the watershed can influence the $\mathrm{CN}$ determination procedure. In this case the estimation of more than one $\mathrm{CN}$ values is needed in order to describe the spatial variability of the watershed and to facilitate the determination procedure.

\subsection{Generalization}

Although the previous analysis is initially restricted for two$\mathrm{CN}$ idealized watershed examples, generally, in natural watersheds could appear more than two $\mathrm{CN}$ value categories. However, every added $\mathrm{CN}$ category requires the determination of two more parameters (the corresponding $\mathrm{CN}$ value and the area it covers), giving rise to the overparameterization problem. Therefore, in a second stage it is investigated if a heterogeneous watershed characterized by three different $\mathrm{CN}$ values can be approached with sufficient accuracy using two $\mathrm{CN}$ value categories. 

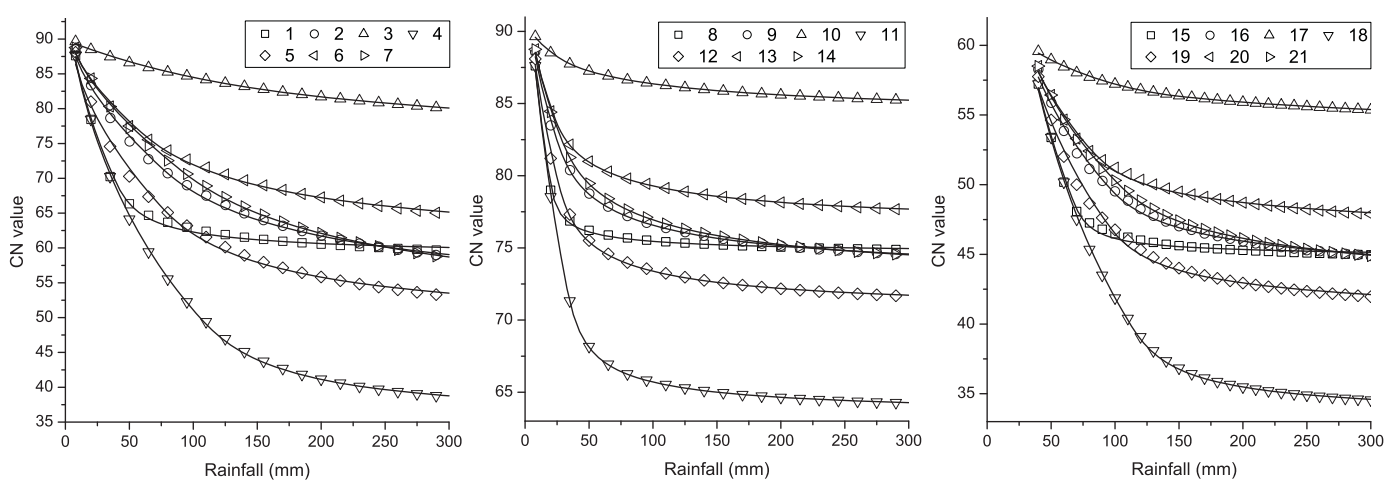

Fig. 4. Two-CN system model curves fitted to the synthetic rainfall-CN data created for the 21 examples of hypothetical watersheds that are characterized by three $\mathrm{CN}$ value categories as described in Table 1.

For this purpose, synthetic runoff data for 21 hypothetical watersheds that are characterized by three $\mathrm{CN}$ value categories have been created. The selected examples cover a wide variety of possible cases including watersheds with various ranges of $\mathrm{CN}$ variation and watersheds dominated by the lower, the medium or the higher $\mathrm{CN}$ value (Table 1). The synthetic runoff data were calculated as the weighted average of the runoff values resulted by the SCS-CN method for the three $\mathrm{CN}$ values characterizing each hypothetical watershed, for rainfall depths ranging from 0 to $300 \mathrm{~mm}$. Then, the corresponding $a, \mathrm{CN}_{\mathrm{a}}$, and $\mathrm{CN}_{\mathrm{b}}$ parameters were determined by fitting the two-CN system model to the synthetic $\mathrm{CN}-\mathrm{P}$ data. As it can be observed in Fig. 4 and at the results presented in Table 1, the synthetic CN- $P$ curves are fitted very well by the two-CN system model in all the examples examined.

In Fig. 5, the synthetic runoff data for six characteristic examples of hypothetical watersheds comprising three $\mathrm{CN}$ value categories are plotted in comparison to the runoff predictions of the SCS-CN method using the single composite $\mathrm{CN}$ value, the single asymptotic $\mathrm{CN}$ value according to Hawkins (1993), the best fitted single $\mathrm{CN}$ value, and the $\mathrm{CN}$ values determined with the two-CN system model. In this figure it can be observed that the SCS-CN method using a single $\mathrm{CN}$ value category can provide adequate results only in the case that one $\mathrm{CN}$ category dominates runoff production in the watershed (e.g. in case 3). In all other cases the use of two $\mathrm{CN}$ categories provides much better results.

\section{Materials and methods}

\subsection{Case studies}

The validity of the above analysis in natural watersheds is investigated in two representative examples, the Little River $\mathrm{N}$ Experimental Watershed and the Lykorrema Experimental Watershed. These watersheds were selected because they have been presented in the literature as examples of the "standard" and the "complacent" behaviour respectively, and for both of them, detailed geographical data were available (Hjelmfelt et al., 2001; Soulis et al., 2009).

\subsubsection{Little river subwatershed $\mathbf{N}$}

The Little River Experimental Watershed (LREW) (Fig. 6a), is one of twelve national benchmark watersheds participating in the Conservation Effects Assessment Project-Watershed Assessment Studies (CEAP-WAS) (Bosch et al., 2007a). It is located near Tifton, Georgia, in the western headwaters area of the Suwannee River Basin, centred at approximately $31.61^{\circ} \mathrm{N}$ and $83.66^{\circ} \mathrm{W}$. The Suwannee River Basin is completely contained in the Gulf-Atlantic Coastal Plain physiographic region, which is characterized by low topographic relief (Sheridan, 1997). Climate in this region is characterized as humid subtropical with an average annual precipitation of about $1167 \mathrm{~mm}$. Hydrology, climate and geographical data at LREW have been monitored by the ARS Southeast Watershed Research Laboratory (SEWRL) since the 1960s (Bosch and Sheridan, 2007; Bosch et al., 2007a, b; Sullivan and Batten, 2007; Sullivan et al., 2007).

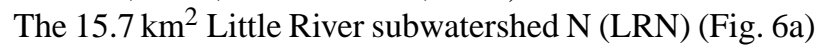
was presented by Hjelmfelt et al. (2001) as a characteristic example of a "standard" watershed. The main soil series in LRN are Tifton loamy sand (48\%), Alapaha loamy sand $(16 \%)$, and Kinston and Osier fine sandy loam (6\%). The agricultural lands are mostly covered by Tifton series soils having moderate infiltration rates (hydrologic soil group B), while the areas around the stream and wetland areas are covered by Alapaha and Kinston-Osier soils (hydrologic soil group D). As it is reported by Lowrance et al. (1984), row crops, pasture, and riparian forests cover approximately 41,13 , and $30 \%$ of LRN, respectively, while the remaining $16 \%$ includes roads, residences, fallow land, and other land cover types. 

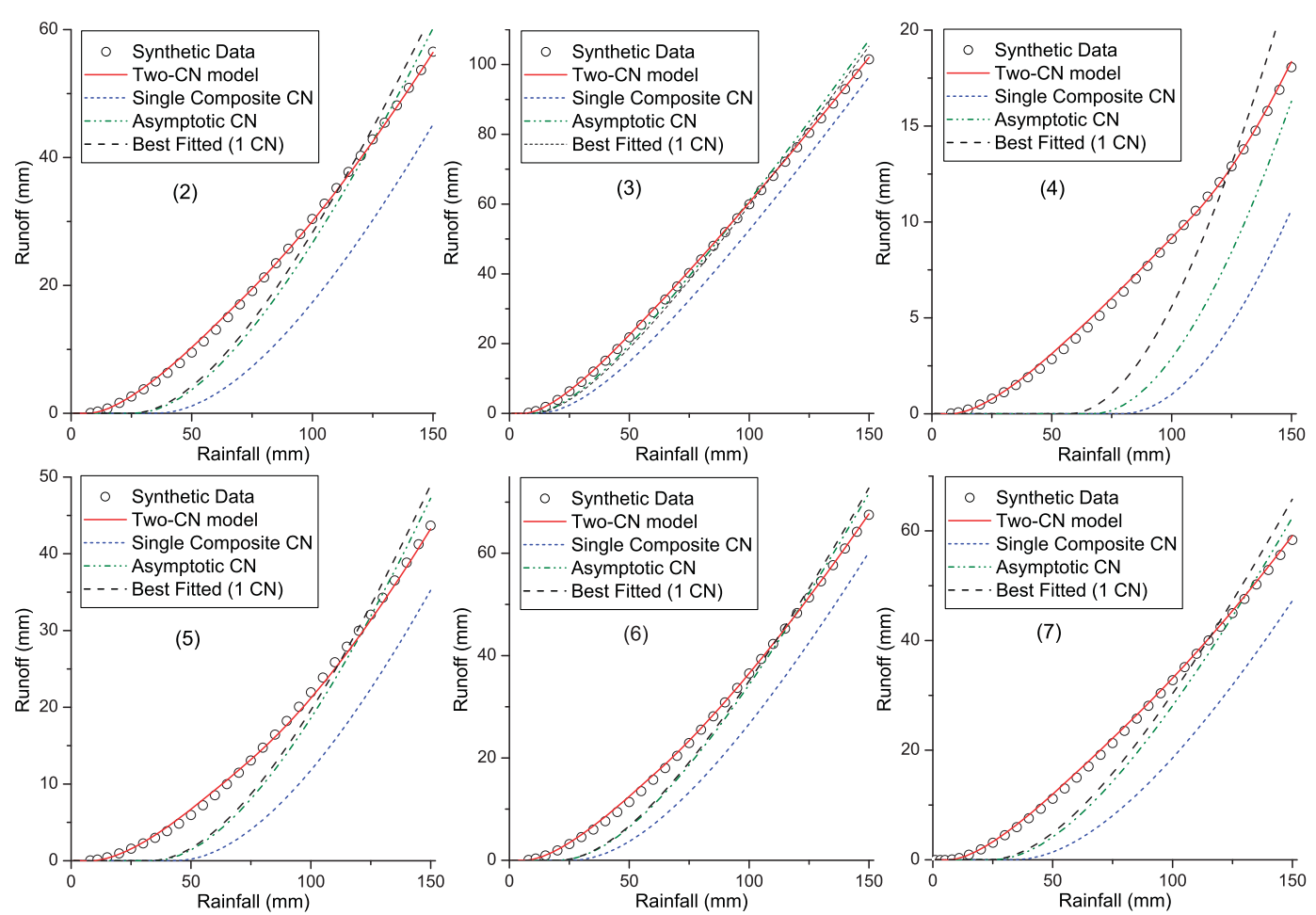

Fig. 5. Synthetic runoff data in comparison to the runoff predictions of the SCS-CN method using the single composite CN value, the single asymptotic CN value according to Hawkins (1993), the best fitted CN value, and the proposed two-CN system model, for six characteristic cases as described in Table 1.

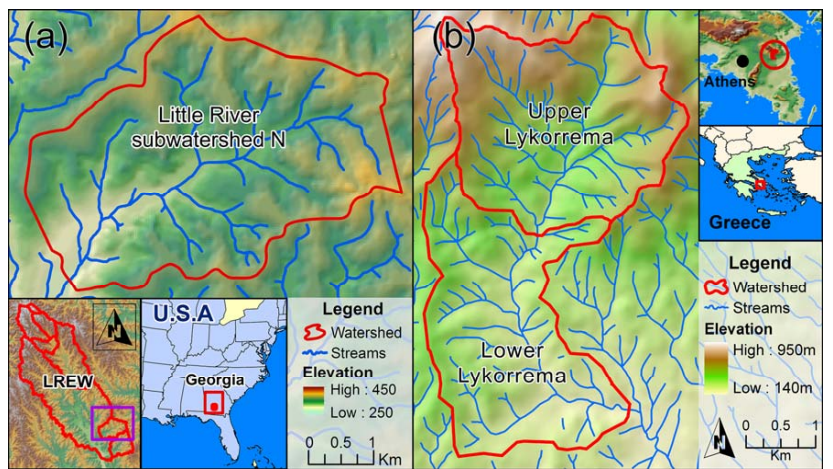

Fig. 6. Map of the case study sites: (a) LRN watershed, (b) Lykorrema experimental watershed.

\subsubsection{Lykorrema, Penteli}

The small scale experimental watershed of Lykorrema stream $\left(15.2 \mathrm{~km}^{2}\right)$, situated in the east side of Penteli Mountain, Attica, Greece, centred at approximately $38.02^{\circ} \mathrm{N}$ and $23.55^{\circ} \mathrm{E}$ (Fig. 6b). The watershed is divided in two sub-watersheds. The Upper Lykorrema watershed $\left(7.84 \mathrm{~km}^{2}\right)$ and the Lower Lykorrema watershed $\left(7.36 \mathrm{~km}^{2}\right)$. The Upper and Lower Lykorrema experimental watersheds are operated from the Agricultural University of Athens, Greece and the National Technical University of Athens, Greece, respectively.
The region is characterized by a Mediterranean semi-arid climate with mild, wet winters and hot, dry summers. The yearly average precipitation value is $595 \mathrm{~mm}$. The watershed presents a relatively sharp relief, with elevations ranging between $146 \mathrm{~m}$ and $950 \mathrm{~m}$. The watershed is dominated by sandy loam soils with high infiltration rates (hydrologic soil group A, 64\%) and a smaller part is covered by sandy clay loam soils presenting relatively high infiltration rates (hydrologic soil group B, 29\%). The dominant land cover type in the watershed is pasture with a few scattered tufts of trees $(93 \%)$. The remaining $7 \%$ includes roads, residences, bare rock and other land cover types. Detailed description of the hydrology, climate and physiography of Lykorrema experimental watershed and of the available geographical and hydro-meteorological databases are provided by Baltas et al. (2007), Soulis (2009), and Soulis et al. (2009).

\subsection{Identification of spatial distribution of $\mathrm{CN}$ along watersheds from measured data using the two-CN system}

In a first attempt a simplified identification procedure is proposed for spatially distribute along the watershed the two$\mathrm{CN}$ categories using the measured $P-Q$ data. The simplified procedure includes the following steps: 


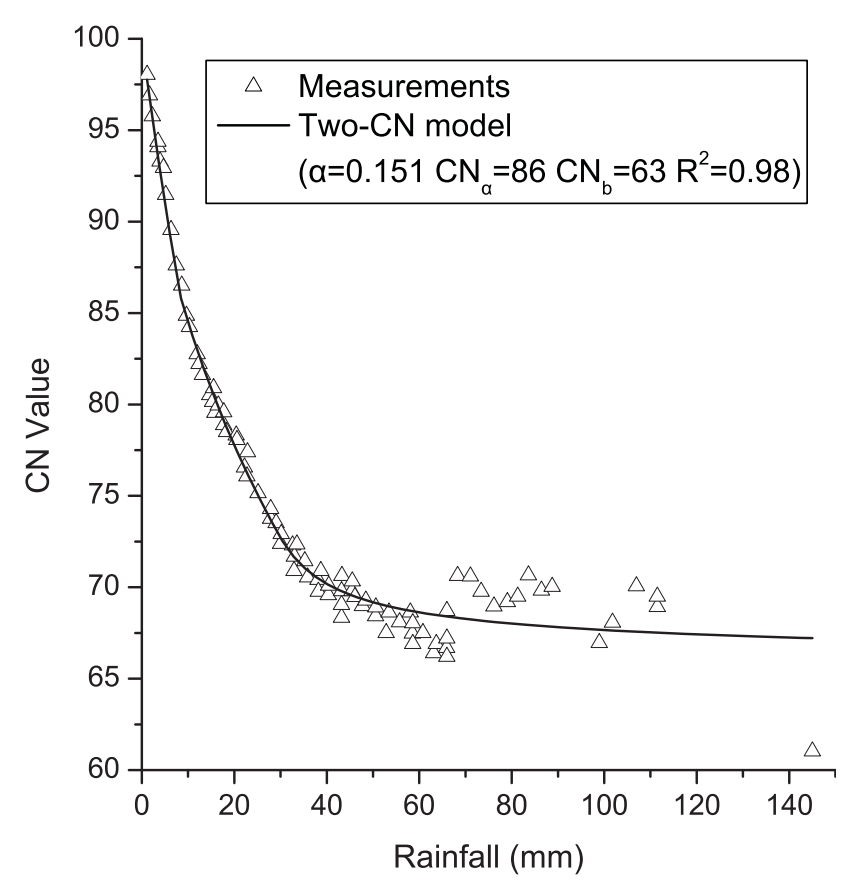

Fig. 7. Two-CN system model fitted to the data presented by Hjelmfelt et al. (2001) for the LRN watershed.

1. The measured $P$ and $Q$ values are sorted separately and then realigned on a rank order basis to form $P-Q$ pairs of equal return period following the frequency matching technique (Hawkins, 1993; Hjelmfelt et al., 1980, 2001). Then the measured $P-Q$ data are transformed in the equivalent $P-\mathrm{CN}$ data using Eq. (6).

2. The two-CN system model (Eq. A1, A2, A3) is fitted to the transformed $\mathrm{CN}-P$ measured data curve yielding a first set of best estimates of parameters $a^{(\circ)}, \mathrm{CN}_{\mathrm{a}}^{(\circ)}$, and $\mathrm{CN}_{\mathrm{b}}^{(\circ)}$ of the model.

3. The watershed is divided in a set of $n$ relatively uniform subareas with constant soil-cover complex. The subareas are clearly spatially identified along the watershed. For each subarea characterized by a specific soilcover complex an initial approximate $\mathrm{CN}^{(\text {table) }}$ value is attributed based on the NEH-4 tables. The areas of all subareas characterized by each specific $\mathrm{CN}^{\text {(table) }}$ value are also determined. The $m$ different $\mathrm{CN}^{\text {(table) }}$ obtained values $(\mathrm{m} \geq 2)$ are put in decreasing order as $\mathrm{CN}_{1}^{\text {(table) }}$, $\mathrm{CN}_{2}^{\text {(table) }}, \ldots \mathrm{CN}_{m}^{\text {(table) }}$ with $\mathrm{CN}_{1}^{(\text {table })}>\mathrm{CN}_{2}^{\text {(table })} \ldots$ $\mathrm{CN}_{m-1}^{(\text {table })}>\mathrm{CN}_{m}^{\text {(table) }}$ and the corresponding cumulative fractions of the watershed, $A_{i}$, characterized by a curve number such as $\mathrm{CN} \geq \mathrm{CN}_{i}^{\text {(table) }}$ are also determined. At each $\mathrm{CN}_{1}^{\text {(table) }}, \mathrm{CN}_{2}^{(\text {table })}, \ldots \mathrm{CN}_{m}^{\text {(table) }}$ values correspond $A_{1}, A_{2}, \ldots, A_{m}$ cumulative fractions area.
4. The $A(i=1, m)$ values are compared to the best estimate fraction parameter $a^{(\circ)}$ and the $A_{i}$ value closer to the $a^{(\circ)}\left(\right.$ e.g. $\left.A_{j}\right)$ is selected.

5. The two-CN system model is once again fitted to the $\mathrm{CN}-P$ measured data curve by fixing the parameter $a=A_{j}$ and treating $\mathrm{CN}_{\mathrm{a}}$ and $\mathrm{CN}_{\mathrm{b}}$ as free parameters leading to $\mathrm{CN}_{\mathrm{a}}^{\text {(distr) }}$, and $\mathrm{CN}_{\mathrm{b}}^{\text {(distr) }}$ best estimate values. It is assumed that all the spatially distributed subareas characterized by $\mathrm{CN} \geq \mathrm{CN}_{j}$ occupying $A_{j}$ cumulative area fraction, are characterized by $\mathrm{CN}$ value identical to the best estimate $\mathrm{CN}_{\mathrm{a}}^{\text {(distr) }}$. The remaining area of the watershed is characterized by the $\mathrm{CN}_{\mathrm{b}}^{(\mathrm{distr})}$ value.

In order to more closely describe the real conditions of natural watersheds it could be proposed using as free parameters three or even four $\mathrm{CN}$ categories to be spatially distributed along the watershed, however such a procedure has an additional risk to appear non-convergence and non-unique solution problems when the inverse solution procedure is applied.

\section{Results}

\subsection{Little River subwatershed N}

Hjelmfelt et al. (2001), using the measured $P-Q$ data obtained the transformed $\mathrm{CN}-P$ measured data curve for the LRN watershed, in a similar way to the first step of the proposed methodology (Fig. 7). Applying the second step of the proposed methodology, the two-CN system model (Eq. A1, $\mathrm{A} 2, \mathrm{~A} 3)$ was fitted to the above mentioned $\mathrm{CN}-\mathrm{P}$ measured data curve presented by Hjelmfelt et al. (2001) (Fig. 7) yielding the best estimates of the three fitting parameters: $a^{(\circ)}=$ $0.151, \mathrm{CN}_{\mathrm{a}}^{(\circ)}=86$, and $\mathrm{CN}_{\mathrm{b}}^{(\circ)}=63$.

At the next step, the approximate values of curve numbers and their spatial distribution along the watershed were initially estimated by selecting them according to the tables and the methodology provided in NEH-4, based on the soil and land cover data contained in the LREW geographical database (Sullivan et al., 2007). Each subarea characterized by different $\mathrm{CN}^{\text {(table) }}$ (as selected from the NEH-4 tables) was spatially identified along the watershed. Figure 8a presents the $\mathrm{CN}^{(\text {table })}$ categories spatial distribution along the watershed. Then the cumulative fraction area for each $\mathrm{CN}^{\text {(table) }}$ category was determined. The cumulative area fractions distribution curve for the various approximate $\mathrm{CN}$ values is presented in Fig. 9. The single composite $\mathrm{CN}$ value was also determined equal to $\overline{\mathrm{CN}}^{\text {(table) }}=71$.

From the cumulative area fraction distribution curve (Fig. 9) the value of $A=0.137$ was selected as the closest value to the value of $a^{(\circ)}=0.151$ obtained using the $P-Q$ measured data, as it is described in the fourth step of the proposed methodology. Then, the two-CN system model 


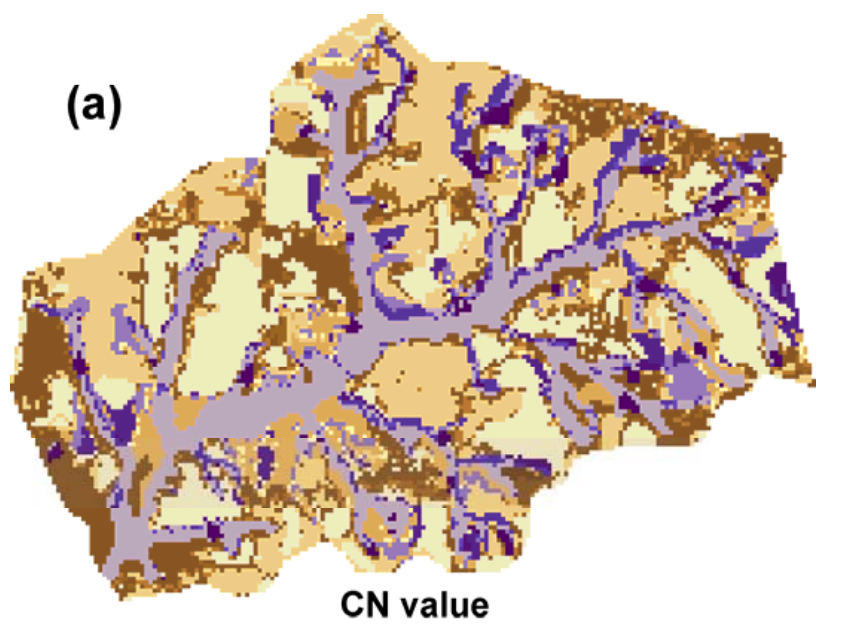

$25 \square 58 \square 62 \square 71 \square 75 \square 78 \square 81 \square 86$

$155 \square 61 \square 70 \square 74 \square 77 \square 80 \square 82 \square 100$

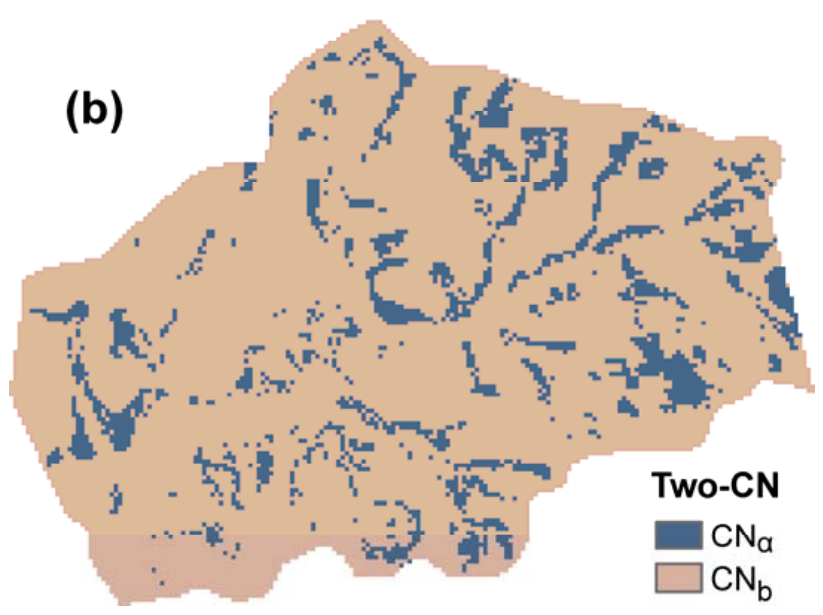

Fig. 8. $\mathrm{LRN}$ watershed $\mathrm{CN}$ value spatial distribution (a) as selected from the NEH-4 tables (b) two-CN system.

(Eq. A1, A2, A3) was once again fitted to the transformed CN- $P$ measured data leading to the parameters $\mathrm{CN}_{\mathrm{a}}^{\text {(distr) }}=$ 87 , and $\mathrm{CN}_{\mathrm{b}}^{\text {(distr) }}=64$ and the spatial distribution of the two $\mathrm{CN}$ values was identified (step 5). Figure $8 \mathrm{~b}$ presents the spatial distribution of the estimated $\mathrm{CN}_{\mathrm{a}}^{(\mathrm{distr})}$ and $\mathrm{CN}_{\mathrm{b}}^{\text {(distr) }}$ parameters.

For comparison reasons, the two composite $\mathrm{CN}$ values corresponding to the area fractions of the watershed equal to $a$ and 1- $a$ were also calculated according to the tables and the methodology provided in NEH-4, and based on the available soil and land cover data. The resulted $\mathrm{CN}$ values were equal to 83 and 69 respectively. These values are comparable to the best estimates of $\mathrm{CN}_{\mathrm{a}}$, and $\mathrm{CN}_{\mathrm{b}}$ parameters' values obtained from the measured $P-Q$ data. The LRN watershed is clearly a heterogeneous watershed with $\mathrm{CN}$ varying between 100 and 55 according to the tables and the methodology provided in NEH-4. The above results provide strong indica-

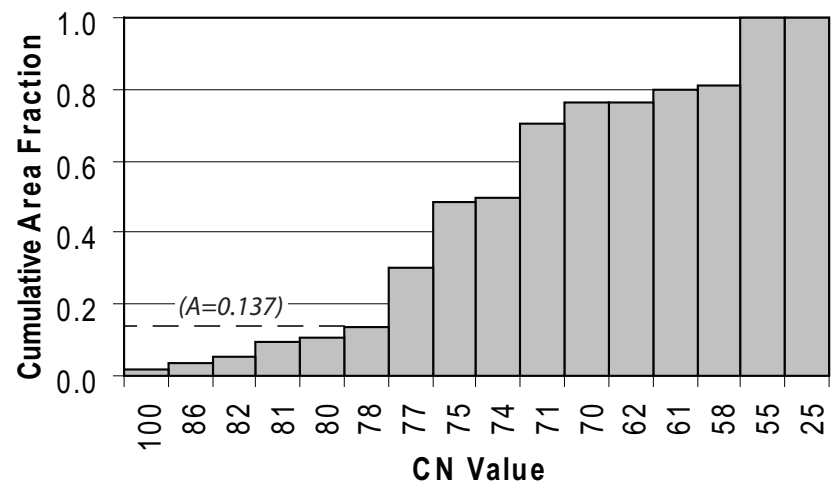

Fig. 9. LRN watershed cumulative area fraction distribution curve.

tions that the observed correlation between the $\mathrm{CN}$ values and the rainfall depths presented in Fig. 7 is essentially related to the spatial variability of the watershed. Additionally, it can be noticed that the estimation of two $\mathrm{CN}$ values can sufficiently describe the spatial variability of the watershed.

\subsection{Lykorrema, Penteli}

Following the first step of the proposed methodology, the measured $Q-P$ data presented by Soulis et al. (2009), were sorted separately and then realigned on a rank order basis to form $P-Q$ pairs of equal return period and then were transformed in the equivalent $P-\mathrm{CN}$ data curve using Eq. (6) (Fig. 10). At the next step, the two-CN system model (Eq. A1, A2, A3) was fitted to the produced $\mathrm{CN}-P$ data curve (Fig. 10) yielding the best estimates of the three fitting parameters: $a^{(\circ)}=0.068, \mathrm{CN}_{\mathrm{a}}^{(\circ)}=97$, and $\mathrm{CN}_{\mathrm{b}}^{(\circ)}=30$ and $a^{(\circ)}=0.10, \mathrm{CN}_{\mathrm{a}}^{(\circ)}=97$, and $\mathrm{CN}_{\mathrm{b}}^{(\circ)}=34$ for the Upper and the Entire Lykorrema watershed respectively.

Then, in the same way as in the previous case study, the approximate values of curve numbers and their spatial distribution along the watershed were initially estimated by selecting them according to the tables and the methodology provided in NEH-4, based on the available soil and land cover data (Soulis, 2009; Soulis et al., 2009). Each subarea characterized by different $\mathrm{CN}^{\text {(table) }}$ (as selected from the NEH-4 tables) was spatially identified along the watershed. Figure 11a presents the $\mathrm{CN}^{\left({ }^{(t a b l e}\right)}$ categories spatial distribution along the watershed. Then the cumulative fraction area for each $\mathrm{CN}^{\text {(table) }}$ category was determined. The cumulative area fractions distribution curve for the various approximate $\mathrm{CN}$ values is presented in Fig. 12. The single composite $\mathrm{CN}$ values were also determined equal to $\overline{\mathrm{CN}}^{\text {(table) }}=51$ and $\overline{\mathrm{CN}}^{\text {(table) }}=55$ for the Upper Lykorrema watershed and for the entire watershed, respectively.

From the cumulative area fraction distribution curve (Fig. 12) the values of $A=0.052$ and $A=0.075$ are selected as the closest values to the corresponding $a^{(\circ)}$ values for the Upper and the Entire Lykorrema watershed respectively, as it 

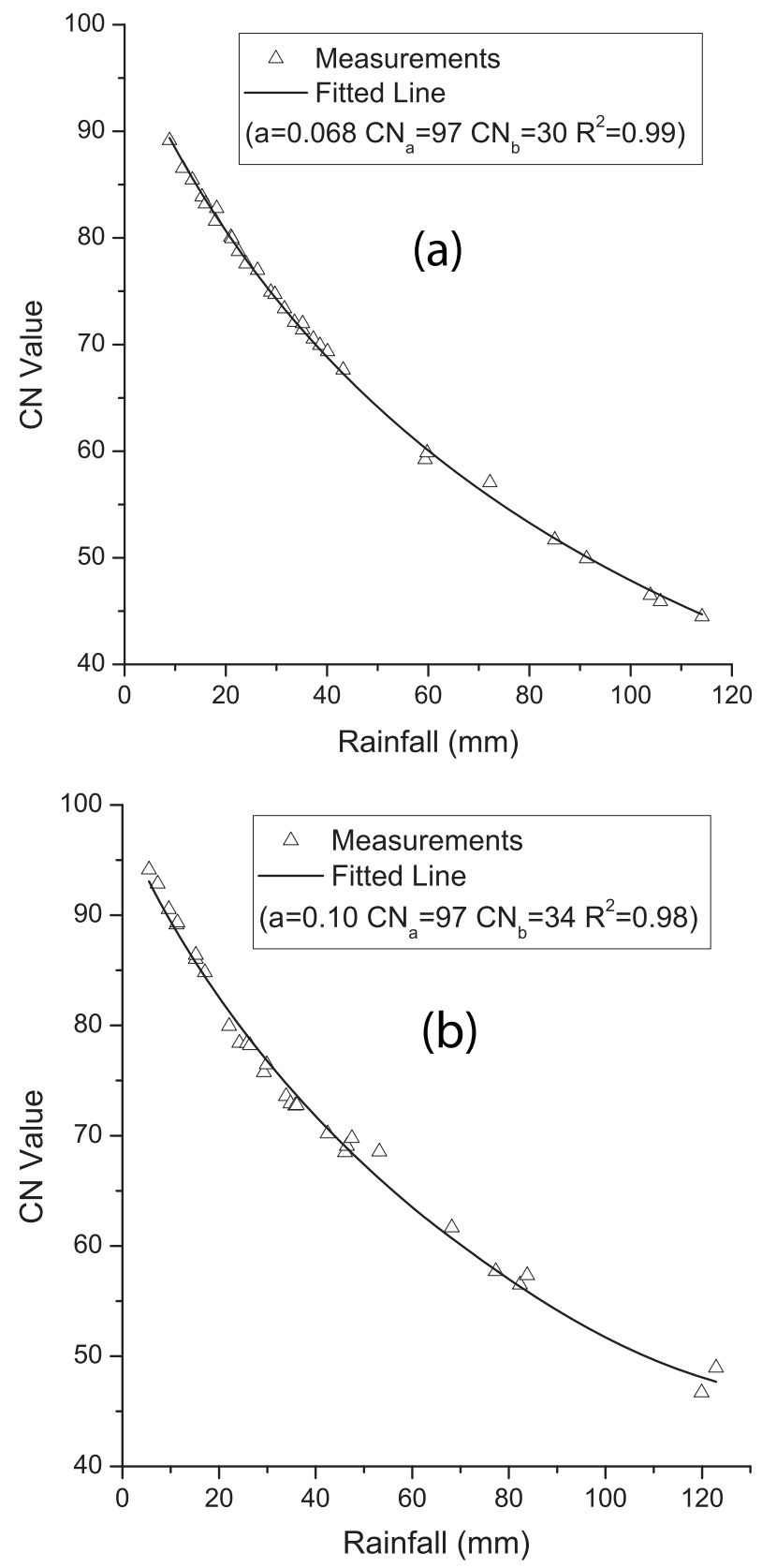

Fig. 10. Two-CN system model fitted to the rainfall-CN data presented by Soulis et al. (2009) for the (a) Upper and (b) Entire Lykorrema watersheds.

is described in the fourth step of the proposed methodology. Then, the two-CN system model (Eq. A1, A2, A3) was once again fitted to the transformed $\mathrm{CN}-P$ measured data leading to the parameters $\mathrm{CN}_{\mathrm{a}}^{\text {(distr) }}=99$ and $\mathrm{CN}_{\mathrm{b}}^{\text {(distr) }}=37$, and $\mathrm{CN}_{\mathrm{a}}^{\text {(distr) }}=100$ and $\mathrm{CN}_{\mathrm{b}}^{\text {(distr) }}=40$ for the Upper and the Entire Lykorrema watershed respectively (step 5). The resulted spatial distribution of the estimated $\mathrm{CN}_{\mathrm{a}}^{\text {(distr) }}$ and $\mathrm{CN}_{\mathrm{b}}^{\text {(distr) }}$ parameters is presented in Fig. 11b.

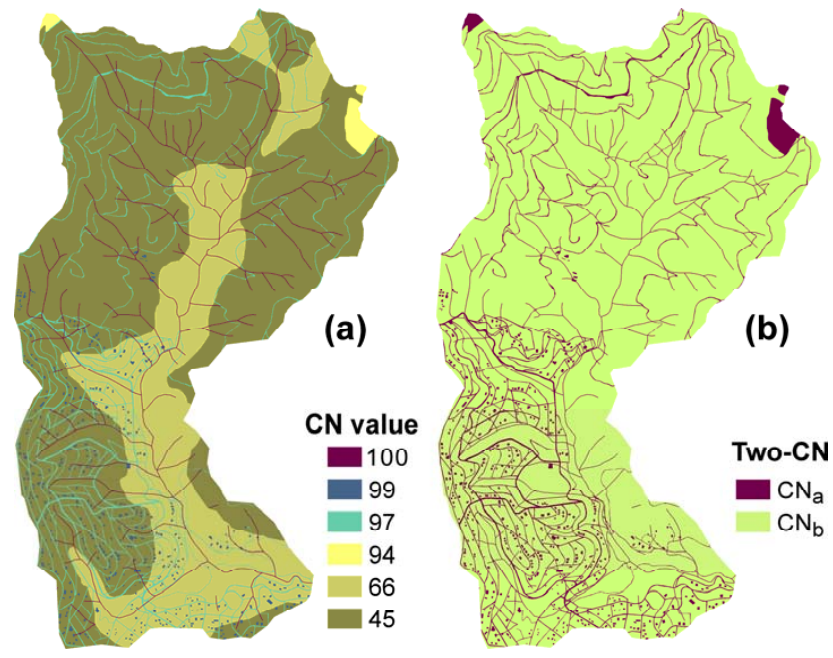

Fig. 11. Lykorrema experimental watershed $\mathrm{CN}$ value spatial distribution (a) as selected from the NEH-4 tables (b) two-CN system.

The Lykorrema watershed is also a heterogeneous watershed with $\mathrm{CN}$ varying between 100 and 45 according to the tables and the methodology provided in NEH-4. Furthermore, it can be observed that the area fractions of the watershed corresponding to the higher best estimate $\mathrm{CN}$ value $\left(\mathrm{CN}_{\mathrm{a}}\right)$ are comparable to the area fractions of the watersheds covered with impervious or nearly impervious surfaces (e.g. roads, buildings, bare rock and stream beds), which are equal to 0.051 and 0.075 for the Upper and the Entire Lykorrema watershed respectively.

In an analogous way as in the LRN case study, the obtained results provide strong indications that the observed correlation between the $\mathrm{CN}$ values and the rainfall depths presented in Fig. 10 is essentially related to the spatial variability of the watersheds and that the estimation of two $\mathrm{CN}$ values can sufficiently describe the spatial variability in both cases.

\section{Discussion}

In this work it is assumed that the specific behaviour in watersheds, according to which $\mathrm{CN}$ systematically varies with rainfall size (Hawkins, 1979, 1993), reflects the effect of the inevitable presence of spatial variability of the soil - cover complexes of watersheds. Since this characteristic of the watershed can be considered invariant in time, therefore in all statistical studies concerning the variation of $\mathrm{CN}$ in a watershed, the produced effect of heterogeneity (e.g. the CN-P relationship) should be included as a deterministic part of the analysis. Other, temporally variant, causes of variability (e.g. rainfall intensity and duration, soil moisture conditions, cover density, stage of growth, and temperature) can explain the remaining scatter around the main rainfall- $\mathrm{CN}$ correlation curve. 


\section{$\square$ Upper Lykorrema $\square$ Entire Lykorrema}
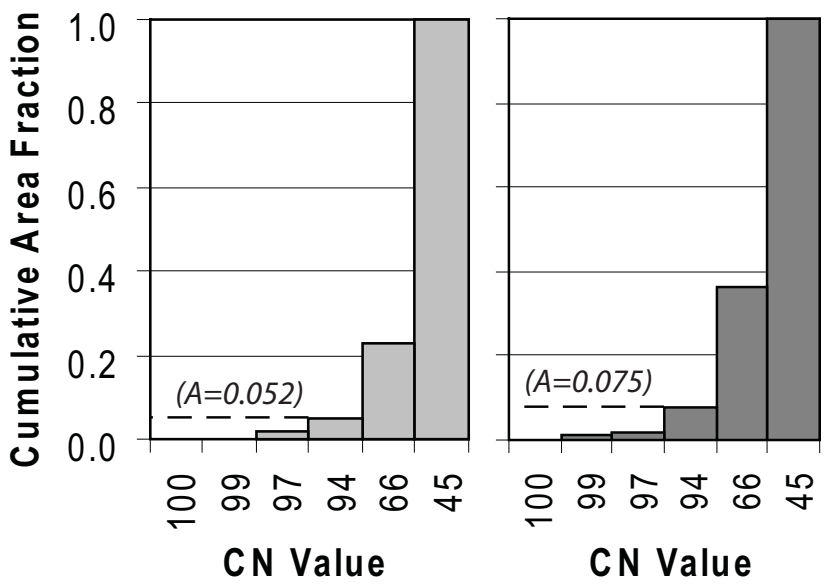

Fig. 12. Lykorrema experimental watershed cumulative area fraction distribution curve.

The concept of a simplified idealized heterogeneous system composed by two different $\mathrm{CN}$ values is introduced. The behaviour of the $\mathrm{CN}-P$ function produced by such a system was analysed systematically and it was found similar to the $\mathrm{CN}-P$ variation observed in natural watersheds (Fig. 1, 7, 10). Measured $P-Q$ data can be used to identify the two different $\mathrm{CN}$ values and the corresponding area fractions of the simplified two-CN system. Then the initial threshold value $\mathrm{CN}_{\circ}$ and the asymptotic large $S$ value of $\mathrm{CN}_{\infty}$ are also obtained and the characteristics of the $\mathrm{CN}(P)$ as well as $Q(P)$ functions are determined.

The proposed method is advantageous over previous methods suggesting the determination of a single asymptotic $\mathrm{CN}_{\infty}$ value to characterize the watershed runoff behaviour as it permits the accurate prediction of runoff for a wider range of rainfall depths (including low and medium rainfall depths) and not for excessively large storms only (it must be noticed that the asymptotic $\mathrm{CN}_{\infty}$ value is essentially observed for excessively large $P>3000 \mathrm{~mm}$ ). Therefore, the proposed method can be also used in continuous hydrological models.

To illustrate if the proposed method of $\mathrm{CN}$ determination in heterogeneous watersheds provides improved runoff predictions over a wider range of rainfall depths than the traditional method that is based on the determination of a single asymptotic $\mathrm{CN}$ value, in Fig. 13, the measured runoff is plotted against the rainfall depth for two "standard" and two "complacent" watersheds" examples presented in the literature. At the same figure the runoff predictions of the SCS$\mathrm{CN}$ method using the $\mathrm{CN}$ values obtained by the proposed $\mathrm{CN}$ determination methodology assuming a two-CN system as well as the runoff predictions of the SCS-CN method based on the determination of a single asymptotic $\mathrm{CN}$ value proposed by Hawkins (1993), are also plotted.

In Fig. 13a can be observed that the proposed methodology over performs the previous original $\mathrm{CN}$ determina- tion method even if the "Coweeta" watershed was selected as a characteristic example of the "standard" behaviour in the study of Hawkins (1993) concerning the asymptotic CN determination method. Furthermore, significant errors are observed for low and medium runoff predictions (for $P<$ $100 \mathrm{~mm}$ ) when the traditional asymptotic method is used. Similar observations can be made in Fig. 13b for the LRN watershed, which was also presented as a characteristic example of the "standard" behaviour by Hjelmfelt et al. (2001) even if the difference in this case is small.

The advantages of the proposed method are more evident in Fig. 13c and d, where two characteristic examples of "complacent" behaviour watersheds presented by Hawkins (1993) and Soulis et al. (2009), respectively, are demonstrated. As it can be clearly seen, satisfactory runoff predictions can be obtained using the $\mathrm{CN}$ values determined by the proposed methodology. In contrast, the $\mathrm{CN}$ values determined with the asymptotic method completely fail to predict runoff. It must be noticed that according to Hawkins (1993) and Hjelmfelt et al. (2001), an asymptotic $\mathrm{CN}$ cannot be determined from data for "complacent" watersheds. For this reason, the runoff predictions obtained based on the best fitted single $\mathrm{CN}$ values were also plotted in Fig. $13 \mathrm{c}$ and d. It can be seen once again that the runoff predictions obtained are very poor in both cases as well. These results are in agreement with the results of the detailed analysis based on synthetic data (Fig. 5) presented in the Sect. 2.4.

In previous analysis it is demonstrated that the presence of heterogeneity produces $\mathrm{CN}-\mathrm{P}$ correlations that stabilize to a steady state regime (asymptotic value) for large values of $P$. Therefore the "complacent" behaviour could be considered as a specific case, in which the available range of rainfall measurements dataset is restricted in such a way that the steady state regime is not yet established and thus an asymptotic $\mathrm{CN}$ value cannot be determined from this dataset.

In Figs. $7 \mathrm{~b}$ and $11 \mathrm{~b}$ the spatial distribution of the estimated $\mathrm{CN}$ values in the two case studies is presented. In these figures, the association of the $a, \mathrm{CN}_{\mathrm{a}}$, and $\mathrm{CN}_{\mathrm{b}}$ parameters to the actual characteristics of the watersheds is highlighted. The ability of the proposed methodology to provide information on the spatial distribution of the estimated $\mathrm{CN}$ values is also demonstrated.

\section{Conclusions}

Considering the theoretical analysis, the systematic analysis using synthetic data and the detailed case studies it can be concluded that the observed correlation between the calculated $\mathrm{CN}$ value and the rainfall depth in a watershed can be attributed to the soils and land cover spatial variability of the watershed and that the proposed two-CN system can sufficiently describe the $\mathrm{CN}$-rainfall variation observed in natural watersheds. The results of the synthetic data analysis (Fig. 5) and the results of the real watersheds examples (Fig. 13) 

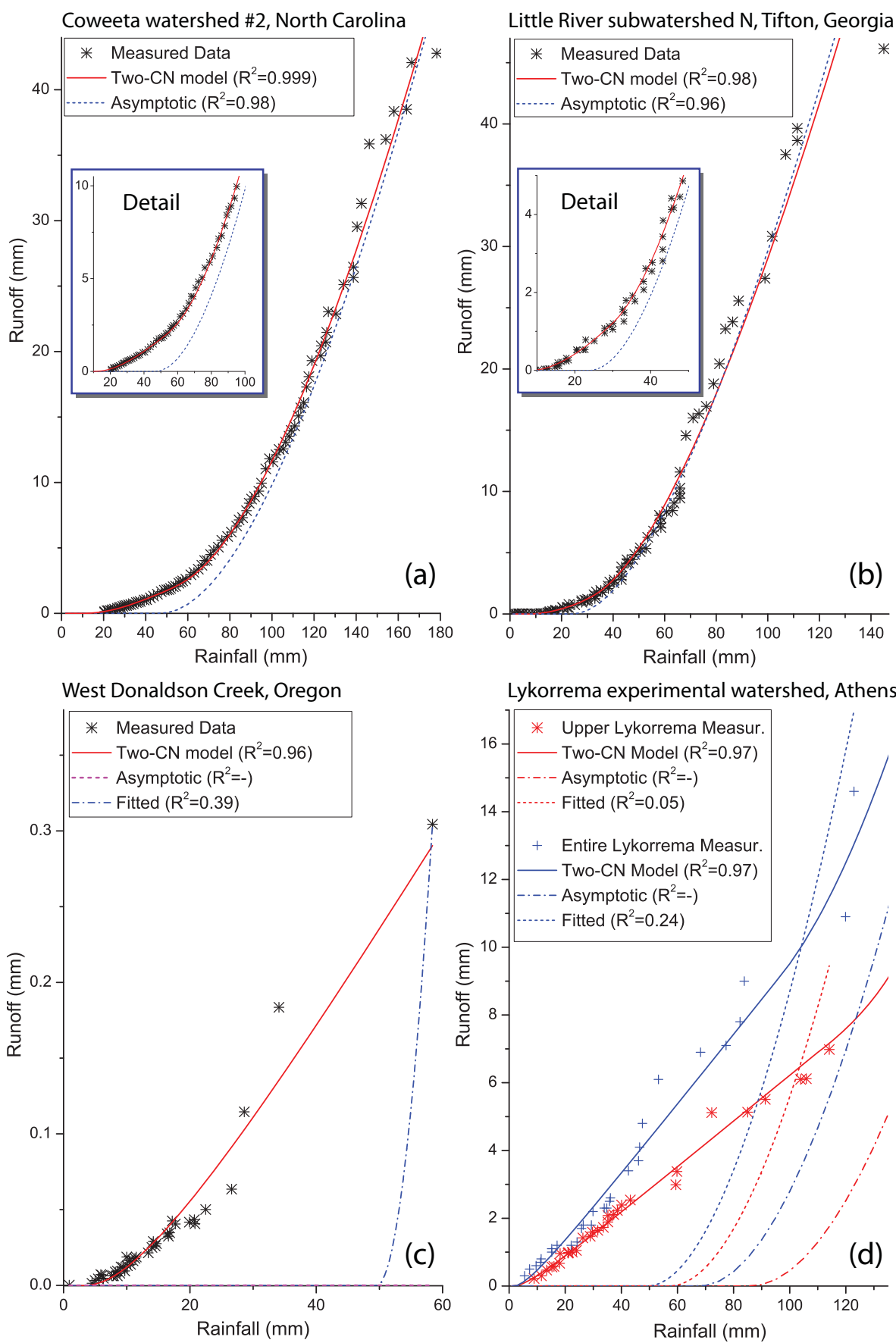

Fig. 13. Measured runoff against the rainfall depth in comparison to the runoff predictions of the various $\mathrm{CN}$ value determination methods for two "standard" (a, b) and two "complacent" $(\mathbf{c}, \mathbf{d})$ watersheds' examples.

indicate that the SCS-CN method using the $\mathrm{CN}$ values obtained by the proposed $\mathrm{CN}$ determination methodology provides superior runoff predictions in most cases and extends the applicability of the original SCS-CN method for a wider range of rainfall depths in heterogeneous watersheds. Furthermore, the proposed methodology allows the $\mathrm{CN}$ determination in "complacent" watersheds. Although the sug- gested method increases the number of unknown parameters to three, a clear physical reasoning for them is presented. A simplified procedure to identify the spatial distribution of the two different $\mathrm{CN}$ values along the watersheds (Fig. 8b, 11b) is also presented. Taking into consideration this additional capability, i.e. to provide information on $\mathrm{CN}$ values spatial distribution and thus spatially 
distributed runoff estimations, the proposed method can be used in other environmental applications e.g. water quality studies or estimation of erosion hazard.

The next step of this approach could be the validation of the proposed methodology to additional experimental watersheds with known characteristics. This is needed for a more definitive validation, and might lead to some adaptations of the proposed conceptual model for explaining the intrinsic correlation of $\mathrm{CN}-P$ data. However, despite these reservations, it is quite interesting that the observed $\mathrm{CN}-P$ correlation in watersheds can be the effect of an intrinsic characteristic of the natural watersheds, which is the spatial heterogeneity. This observation may facilitate future studies aiming at the extension of the SCS-CN method documentation for different regions and different soil, land use, and climate conditions.

\section{Appendix A}

\section{Two-CN system fitting model}

Equations of the two-CN system fitting model to the transformed $\mathrm{CN}-P$ data with free parameters $a, \mathrm{CN}_{\mathrm{a}}$, and $\mathrm{CN}_{\mathrm{b}}$. The initial abstraction rate was set to the standard value of $\lambda=0.2$.

$\mathrm{CN}=\frac{25400}{5\left(P+2\left(Q_{\mathrm{a}}+Q_{\mathrm{b}}\right)-\sqrt{4\left(Q_{\mathrm{a}}+Q_{\mathrm{b}}\right)^{2}+5 P\left(Q_{\mathrm{a}}+Q_{\mathrm{b}}\right)}\right)+254}$

where:

$$
\begin{array}{r}
Q_{\mathrm{a}}=0 \quad \text { if } \quad 0.2 P<\frac{25400}{\mathrm{CN}_{\mathrm{a}}}-254 \\
Q_{\mathrm{a}}=\alpha \frac{\left(P-0.2\left(\frac{25400}{\mathrm{CN}_{\mathrm{a}}}-254\right)\right)^{2}}{P+0.8\left(\frac{25400}{\mathrm{CN}_{\mathrm{a}}}-254\right)} \\
\text { if } \quad 0.2 P \geq \frac{25400}{\mathrm{CN}_{\mathrm{a}}}-254
\end{array}
$$

and

$$
\begin{array}{r}
Q_{\mathrm{b}}=0 \quad \text { if } \quad 0.2 P<\frac{25400}{\mathrm{CN}_{\mathrm{b}}}-254 \\
Q_{\mathrm{b}}=(1-a) \frac{\left(P-0.2\left(\frac{25400}{\mathrm{CN}_{\mathrm{b}}}-254\right)\right)^{2}}{P+0.8\left(\frac{25400}{\mathrm{CN}_{\mathrm{b}}}-254\right)} \\
\text { if } \quad 0.2 P \geq \frac{25400}{\mathrm{CN}_{\mathrm{b}}}-254
\end{array}
$$

Acknowledgements. The authors wish to thank the editor and the reviewers for their constructive and insightful comments.

Edited by: M. Werner

\section{References}

Abon, C. C., David, C. P. C., and Pellejera, N. E. B.: Reconstructing the Tropical Storm Ketsana flood event in Marikina River, Philippines, Hydrol. Earth Syst. Sci., 15, 1283-1289, doi:10.5194/hess-15-1283-2011, 2011.

Adornado, H. A. and Yoshida, M.: GIS-based watershed analysis and surface run-off estimation using curve number $(\mathrm{CN})$ value, J. Environ. Hydrol., 18, 1-10, 2010.

Baltas, E. A., Dervos, N. A., and Mimikou, M. A.: Technical note: Determination of the SCS initial abstraction ratio in an experimental watershed in Greece, Hydrol. Earth Syst. Sci., 11, 18251829, doi:10.5194/hess-11-1825-2007, 2007.

Bonta, J. V.: Determination of watershed Curve Number using derived distribution, J. Irrig. Drain. Eng. ASCE, 123, 28-36, 1997.

Bosch, D. D. and Sheridan, J. M.: Stream discharge database, Little River Experimental Watershed, Georgia, United States, Water Resour. Res., 43, W09473, doi:10.1029/2006WR005833, 2007.

Bosch, D. D., Sheridan, J. M., Lowrance, R. R., Hubbard, R. K., Strickland, T. C., Feyereisen, G. W., and Sullivan D. G.: Little River Experimental Watershed database, Water Resour. Res., 43, W09470, doi:10.1029/2006WR005844, 2007a.

Bosch, D. D., Sheridan, J. M., and Marshall, L. K.: Precipitation, soil moisture, and climate database, Little River Experimental Watershed, Georgia, United States, Water Resour. Res., 43, W09472, doi:10.1029/2006WR005834, 2007b.

Chen, C. L.: An evaluation of the mathematics and physical significance of the Soil Conservation Service curve number procedure for estimating runoff volume, Proc., Int. Symp. on RainfallRunoff Modeling, Water Resources Publ., Littleton, Colo., 387418, 1982.

Elhakeem, M. and Papanicolaou, A. N.: Estimation of the runoff curve number via direct rainfall simulator measurements in the state of Iowa, USA, Water Resour. Manag., 23, 2455-2473, 2009.

Grove, M., Harbor, J., and Engel, B.: Composite vs. Distributed curve numbers: Effects on estimates of storm runoff depths, J. Am. Water Resour. As., 34, 1015-1023, 1998.

Hawkins, R. H.: Runoff curve numbers for partial area watersheds, J. Irrig. Drain. Div. ASCE., 105, 375-389, 1979.

Hawkins, R. H.: Asymptotic determination of runoff curve numbers from data, J. Irrig. Drain. Eng. ASCE, 119, 334-345, 1993.

Hjelmfelt Jr., A. T.: Empirical investigation of curve number technique, J. Hydraul. Div. ASCE, 106, 1471-1476, 1980.

Hjelmfelt Jr., A. T.: Investigation of curve number procedure, J. Hydraul. Eng. ASCE, 117, 725-737, 1991.

Hjelmfelt Jr., A. T., Woodward, D. A., Conaway, G., Plummer, A., Quan, Q. D., Van Mullen, J., Hawkins, R. H., and Rietz, D.: Curve numbers, recent developments, in: Proc. of the 29th Congress of the Int. As. for Hydraul. Res., Beijing, China (CD ROM), 17-21 September, 2001.

Holman, P., Hollis, J. M., Bramley, M. E., and Thompson, T. R. E.: The contribution of soil structural degradation to catchment flooding: a preliminary investigation of the 2000 floods in England and Wales, Hydrol. Earth Syst. Sci., 7, 755-766, doi:10.5194/hess-7-755-2003, 2003.

King, K. W. and Balogh, J. C.: Curve numbers for golf course watersheds, T. ASAE, 51, 987-996, 2008.

Lantz, D. G. and Hawkins R. H.: Discussion of "Long-Term Hydrologic Impact of Urbanization: A Tale of Two Models" J. Water 
Res. Pl., ASCE, 127, 13-19, 2001.

Lowrance, R., Todd, R., Fail, J., Hendrickson, O., Leonard, R., and Asmussen, L.: Riparian Forests as Nutrient Filters in Agricultural Watersheds, BioScience, 34, 374-377, 1984.

McCuen, R. H.: Approach to confidence interval estimation for curve numbers, J. Hydrol. Eng., 7, 43-48, 2002.

Michel, C., Andréassian, V., and Perrin, C.: Soil Conservation Service Curve Number method: How to mend a wrong soil moisture accounting procedure?, Water Resour. Res., 41, W02011, doi:10.1029/2004WR003191, 2005.

Mishra, S. K. and Singh, V. P.: Another look at SCS-CN method, J. Hydrol. Eng. ASCE, 4, 257-264, 1999.

Mishra, S. K. and Singh, V. P.: Long-term hydrological simulation based on the soil conservation service curve number, Hydrol. Process., 18, 1291-1313, 2004.

Moretti, G. and Montanari, A.: Inferring the flood frequency distribution for an ungauged basin using a spatially distributed rainfall-runoff model, Hydrol. Earth Syst. Sci., 12, 1141-1152, doi:10.5194/hess-12-1141-2008, 2008.

Ponce, V. M. and Hawkins, R. H.: Runoff curve number: Has it reached maturity?, J. Hydrol. Eng. ASCE, 1, 11-18, 1996.

Romero, P., Castro, G., Goìmez, J. A., and Fereres, E.: Curve number values for olive orchards under different soil management, $\mathrm{S}$. Sci. Soc. Am. J. 71, 1758-1769, 2007.

SCS: National Engineering Handbook, Section 4: Hydrology, Soil Conservation Service, USDA, Washington, D.C., 1956.

SCS: National Engineering Handbook, Section 4: Hydrology, Soil Conservation Service, USDA, Washington, D.C., 1964.

SCS: National Engineering Handbook, Section 4: Hydrology, Soil Conservation Service, USDA, Washington, D.C., 1971.

SCS: National Engineering Handbook, Section 4: Hydrology, Soil Conservation Service, USDA, Washington, D.C., 1985.

SCS: National Engineering Handbook, Section 4: Hydrology, Soil Conservation Service, USDA, Washington, D.C., 1993.

SCS: National Engineering Handbook, Section 4: Hydrology, Soil Conservation Service, USDA, Washington, D.C., 2004.

Sheridan J. M.: Rainfall-streamflow relations for coastal plain watersheds, Appl. Eng. Agric., 13, 333-344, 1997.
Soulis, K. X.: Water Resources Management: Development of a hydrological model using Geographical Information Systems, Ph.D. Thesis, Agricultural University of Athens, Greece, 2009.

Soulis, K. X. and Dercas, N.: Development of a GIS-based spatially distributed continuous hydrological model and its first application, Water Int.. 32, 177-192, 2007.

Soulis, K. X., Valiantzas, J. D., Dercas, N., and Londra P. A.: Analysis of the runoff generation mechanism for the investigation of the SCS-CN method applicability to a partial area experimental watershed, Hydrol. Earth Syst. Sc. 13, 605-615, doi:10.5194/hess-13-605-2009, 2009.

Steenhuis, T. S., Winchell, M., Rossing, J., Zollweg, J. A., and Walter, M. F.: SCS runoff equation revisited for variable-source runoff areas, J. Irrig. Drain. Eng. ASCE, 121, 234-238, 1995.

Sullivan, D. G. and Batten, H. L.: Little River Experimental Watershed, Tifton, Georgia, United States: A historical geographic database of conservation practice implementation, Water Resour. Res., 43, W09475, doi:10.1029/2007WR006143, 2007.

Sullivan, D. G., Batten, H. L., Bosch, D., Sheridan, J., and Strickland, T.: Little River Experimental Watershed, Tifton, Georgia, United States: A geographic database, Water Resour. Res., 43, W09471, doi:10.1029/2006WR005836, 2007.

Tramblay, Y., Bouvier, C., Martin, C., Didon-Lescot, J. F., Todorovik, D., and Domergue, J. M.: Assessment of initial soil moisture conditions for event-based rainfall-runoff modelling, J. Hydrol., 387, 176-187, 2010.

van Dijk, A. I. J. M.: Selection of an appropriately simple storm runoff model, Hydrol. Earth Syst. Sci., 14, 447-458, doi:10.5194/hess-14-447-2010, 2010.

Woodward, D. E., Hawkins, R. H., Jiang, R., Hjelmfelt, A. T. Jr., Van Mullem, J. A., and Quan D. Q.: Runoff Curve Number Method: Examination of the Initial Abstraction Ratio, World Water \& Environ. Resour. Congress 2003 and Related Symposia, EWRI, ASCE, 23-26 June, 2003, Philadelphia, Pennsylvania, USA, doi:10.1061/40685(2003)308, 2003.

Yu, B.: Theoretical justification of SCS-CN method for runoff estimation, J. Irrig.. Drain. Div. ASCE., 124, 306-310, 1998. 